\title{
Misunderstandings on Consent to Treatment in the Mental Health Act 1983
}

\author{
P. M. Jefperys, Consultant Psychiatrist, Northwick Park Hospital and Clinical Research Centre, Harrow, Middlesex
}

Part IV of the 1983 Mental Health Act (Sections 56-64) introduces new safeguards and procedures relating to Consent to Treatment for detained patients and in limited situations to informal patients. Many psychiatrists have expressed misgivings about these provisions and many are unfamiliar with the new requirements. One medical member of the Mental Health Act Commission visited twenty different hospitals for the purposes of issuing a Certificate of Second Opinion during a four-month period between October 1983 and February 1984. This paper discusses some of the practices and misunderstandings encountered.

\section{Applicability of Section 58}

Example A: The detained patient gives informed consent for ECT and signs the hospital consent form and therefore no additional Certificate is required. Comment: Mistaken-in these circumstances the responsible medical officer (RMO) must also complete Form 38 (Certificate of Consent to Treatment).

Example B: The detained patient agrees to take oral psychotropic medication (after three months) and therefore no additional certificate is required. Comment: Mistaken-in these circumstances the RMO must also complete Form 38 after confirming the patient's consent.

Example C: Certification is only required (after three months) for medicines administered by injection. Comment: Mistaken-certification is required (after three months) for any medicine administered for mental disorder by whatever route.

Example D: Certification is not required for detained patients on extended leave. Comment: Mistaken-a patient on extended leave is still liable to be detained and certification by RMO or MHAC appointed doctor is required.

Example E: If a Certificate of Second Opinion (Form 39) is issued for a course of ECT it can still cover a second course of ECT if thought necessary by the RMO. Comment: Mistaken-a new course of ECT following a gap of three weeks or more after the last ECT treatment requires fresh certification.

Example F: A stuporose detained patient unable to give consent can be given ECT without certification provided the nearest relative agrees with the RMO's plan. Comment: Mistaken-in these circumstances a second opinion must be sought from MHAC doctor, but treatment might be started under provisions of Section 62 (1).

Section 58 and medicines - timing of three months

Example G: Certification is not required until the patient has been on the same drug (or class of drugs) for three months, even if other psychotropic drugs were given earlier in the period of detention. Comment: Mistaken-certification is required three months after any medicine for mental disorder has been given while the patient is subject to detention.

Example H: A medication-free period during a period of detention (but following earlier medication) does not count towards the three months when certification will be required. Comment: Mistaken.

\section{Certification requirements}

Example J: A consenting patient must sign Form 38, Certificate of Consent. Comment: Mistakenno requirement to do so.

Example K: A consenting patient to medicines must sign a written hospital consent form. Comment: Mistaken-no requirement to do so.

Example L: A Senior Registrar or junior doctor can complete Form 38, Certificate of Consent, on behalf of the Consultant. Comment: Mistaken-only the RMO (doctor in charge of the patient's treatment) can do so or an appointed doctor from the MHAC.

Example M: A patient consents to oral medication but not long-acting injections (after three months). The RMO issues a Certificate of Consent (Form 38) for oral medication and asks the MHAC appointed doctor for a Certificate of Second Opinion (Form 39) to cover the injections. Comment: Mistaken - the RMO should ask the MHAC appointed doctor to consider a treatment plan covering all aspects of medical treatment and only one certificate should be issued.

Example N: Fresh certification is not required if the RMO wishes to change the treatment to a different class of drug with the patient's agreement and a previous Certificate of Consent (Form 38) 
has been issued, which does not include the new class of drug. Comment: Mistaken-treatment with a new class of drug represents a new form of treatment and requires a fresh Certificate of Consent (Form 38).

Example O: The RMO obtains an independent second opinion from a consultant colleague who supports the plan to treat the non-consenting patient with ECT. The latter completes Form 39 (Certificate of Second Opinion) and treatment proceeds. Comment: Mistaken-a Certificate of Second Opinion can only be issued by a doctor appointed by the MHAC (under Section 121 (2)) on behalf of the Secretary of State.

\section{Use of Section 62 (Urgent Treatment)}

Example P: A detained patient is given ECT as an emergency (under Section 62). Section 62 then covers the remainder of the course and consent under Section 58 is not required. Comment: Mistaken-the MHAC appointed doctor should see the patient as soon as possible and decide whether treatment should continue with the issue of Form 39 (Certificate of Second Opinion).

Example Q: Section 62 sanctions the use of medication in emergency for any non-consenting detained patient. Comment: Mistaken-Section 62 does not cover patients held under Section 5 (4) (Nurse Holding Power); Section 5 (2); Section 4; Section 135 or Section 136. Common-law powers may apply here.

\section{Monitoring of Section 58 and Section 62}

Only two of the hospitals had developed procedures for centrally monitoring the issue of Form 38 Certificates and none were asking medical staff to positively inform them of the use of Section 62. Two-thirds of the hospitals had not developed a centrally organized flagging procedure to ensure that the RMOs were informed in good time of the three months' detention.

All views and opinions expressed in this article are those of the author and are not necessarily those of the Mental Health Act Commission.

\section{Attitudes of British and Nigerian Teachers to Training African Psychiatrists in the UK*}

JoHn L. Cox, Senior Lecturer, Department of Psychiatry, Royal Edinburgh Hospital and O. O. FAmUYiwA, Senior Research Associate, Nuffield Psychology and Psychiatry Unit, Fleming Memorial Hospital, Newcastle upon Tyne

The increased fees for postgraduate trainees from overseas and their difficulty passing the MRCPsych examination have made some British teachers question whether Departments of Psychiatry should continue to provide training for such doctors. The change in the relationship between old and new Commonwealth countries, and the increased availability of postgraduate training in Nigeria, Kenya or Zimbabwe are other factors to be considered.

Since one of the authors (J.C.) had previously worked in Africa, and was now in Edinburgh, and the other (O.F.), having trained in Edinburgh, was a Lecturer in Nigeria, we had the opportunity to determine the attitudes of teachers towards training of overseas psychiatrists in Britain. In preparation for the African Psychiatry Association Conference a brief questionnaire was devised and sent to British and Nigerian tutors and Professors of Psychiatry. Specialist teachers were not included in the survey. The questionnaire was restricted to determining the attitudes to training sponsored overseas psychiatrists in Britain only, and not overseas psychiatrists working in a National Health Service

"This article is based on a paper read at the African Psychiatry Association meeting held in London in July 1983. post. The sponsored overseas psychiatrists were usually funded by their own Government, British Council, World Health Organization or the Association of Commonwealth Universities.

All teachers were asked whether a University Department of Psychiatry in Britain or teaching hospital had a responsibility to provide training for sponsored overseas psychiatrists, and to give reasons for their answer. Other items included an enquiry about the teacher's attitude to the suitability for an African trainee of the MRCPsych examination, and the possible benefits for a British trainee from working in Africa. British teachers were also asked how many sponsored overseas psychiatrists had been trained in the last five years.

The only biographical information obtained was the teachers' present post and the place of their first medical qualification.

The Nigerians received a questionnaire similar to that sent to UK teachers, but were also asked to describe any limitations of the postgraduate training in Nigeria.

\section{Attitudes of British teachers \\ Of the 201 British teachers who received our question-}

